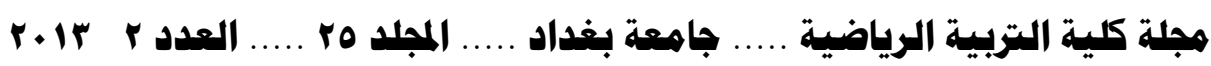

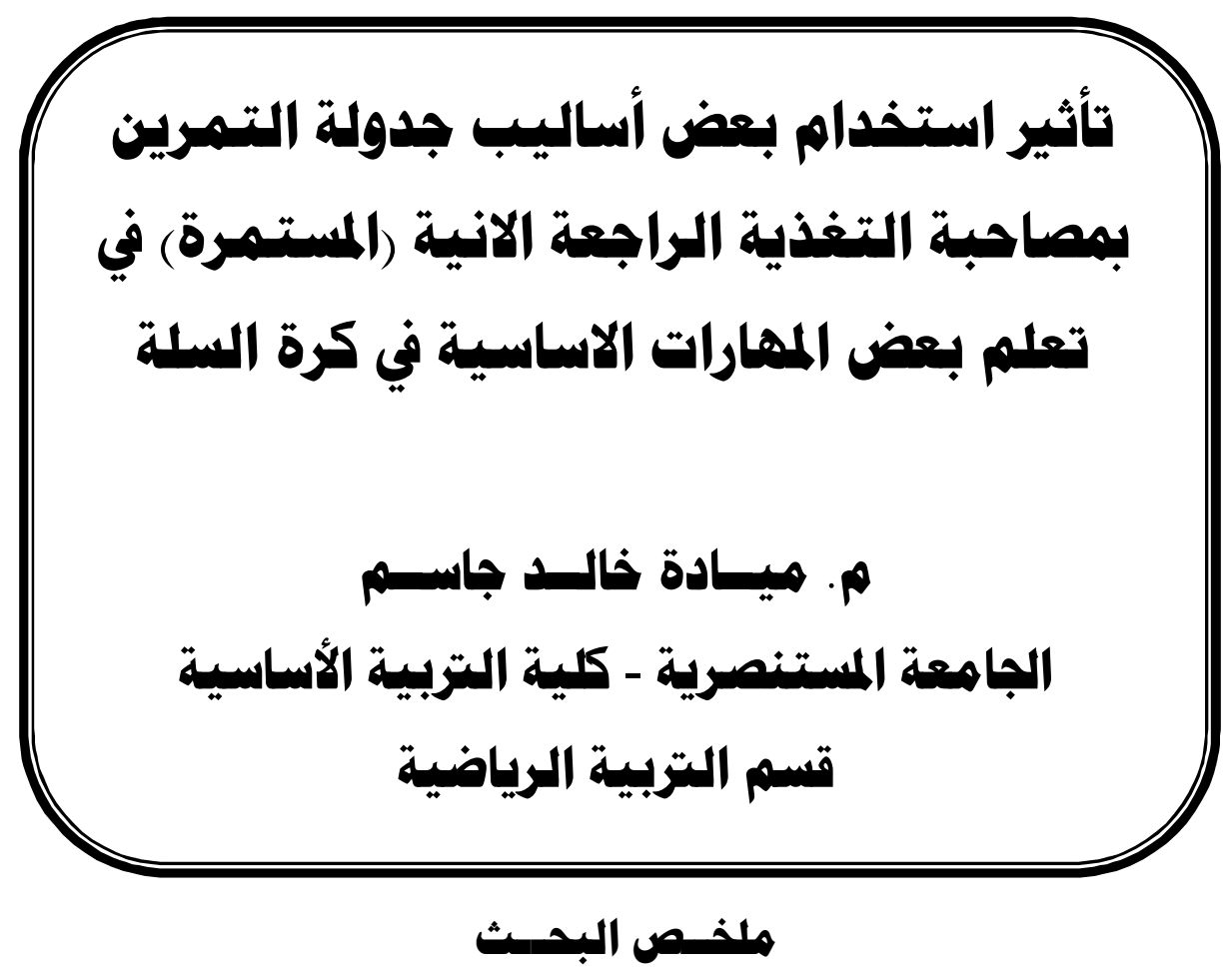

الباب الاول

تضمن هذا الباب المقدمه واهميه البحث حيث تم التطرق الى طرائق واساليب التربيه الرياضيه واهميه اعداد المعلمين حسب الطرق والاساليب المستخدمة في التعلم الحركي وذلك لأهمية هذه الطرق والاساليب في تحقيق نتائج افضل في تعلم المهارات. وتتحدد المشكلة للبحث في ان الاسلوب التقليدي هو الاكثر شيوعا واستخداما في تدريس منهاج التربية الرياضية وان اساليب جدولة التمرين التي ظهرت حديثا ومن ضمنها التدريب المكثف والموزع لم تلث اهتماما ملحوظا من جانب المهتمين برياضة كرة السلة ولا تستعمل الافي نطاق محدود خصوصا اذا تزامن مع استخدام هاتين الطريقتين تزويد المتعلم بمعلومات حول أدائه بشكل أني ومستمر المي 


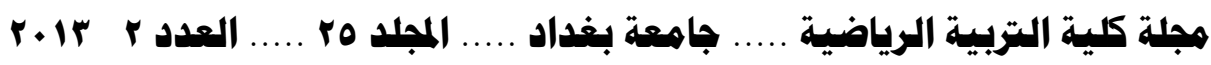

هداف البحث

ا ـ التعرف على تـأثير التدريب المكثف المصاحب للتغذيـة الراجعة الانيـة(المستمرة)

في تعلم بعض المهارات بكرة السلة .

ץ. التعرف على تأثير التدريب الموزع المصاحب للتغذيـة الراجعة الانيـة(المستمرة)

في تعلم بعض المهارات بكرة السلة .

فروض البحث

ا. هنـاك فروق ذات دلالـة احصائية بـين الاختبـارات القبليـة والبعديـة للمجموعتين

التجريبيتين ولصالح الاختبارات البعدية .

r. هناك فروق ذات دلالة احصائية بين الاختبارات البعدية للمجموعتين التجريبيتين

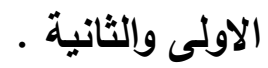

مجالات البحث

1-ع - المجال البشري:- طلاب المرحلة الاولى في قسم التربية الرياضية كلية التربية

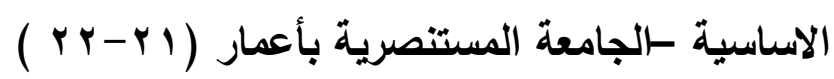

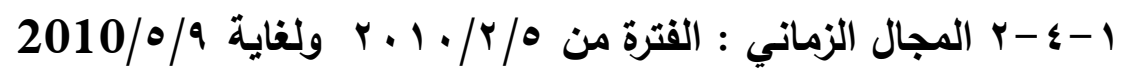

1-ع - المجال المكاني القاعة الرياضية المغلقة لكلية التربية الاساسية في قسم التربية الرياضية الجامعة المستنصرية

الباب الثاني

الاطار النظري وقد تضمن طرائق التعلم الحركي (جدولة التمرين ) ،وكذلك تناولت الباحثة المهارات الاساسية الخاصة بلعبة كرة السلة شيء من الحديث . الباب الثالث

استخدمت الباحثة المنهج التجريبي وقد تكونت من مجموعتين تجريبيتين وكل مجموعة متكونة من (0) طالبة بحيث يكون تدريس المجموعة التجريبية الاولى بطريقة 


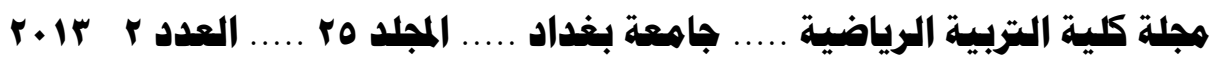

التدريب المكثف المصاحب للتغذية الراجعة الانية (المستمرة) والمجموعة التجريبية الثانية بطريقة التدريب الموزع المصاحب للتغذية الراجعة الانية (المستمرة) وتم التجانس بين المجموعتين في متغيرات (الطول والوزن والعمر)واستخدمت الباحثة التصميم التجريبي المسمى (اسلوب المجموعات المتجانسة) تم ضبط المتغيرات التي تؤثر في السلامة الداخلية والخارجية للتصميم التجريبي كذلك احتوى هذا الباب على التجربة الاستطلاعية والبرنامج التعليمي وتجربة البحث الرئيسية وتقويم مستوى الاداء والوسائل الاحصائية. الباب الرابع

تم في هذا الباب عرض النتائج ومناقشتها وتحليليها وصولا الى تحقيق اهداف

$$
\text { البحث وفروضه. }
$$

من خلال نتائج البحث خرج الباحثة بـ(استنتاجين) منها ا - ان التدريبين (المكثف والموزع ) بمصاحبة للتغذية الراجعة الانية(المستمرة) لهما تأثير في تعلم مهارتي الطبطبة المنخفضة والمناولة الصدرية بكرة السلة ץ- ان التدريب الموزع المصاحب للتغذية الراجعة الانية(المستمرة) هو الافضل في تعلم مهارتي الطبطبة المنخفضة والمناولة الصدرية بكرة السلة . كذلك خرجو ا بـ (ثلاث توصيات منها): 1 - توصي الباحثة باستخدام التدريب الموزع بمصاحب للتغذية الراجعة الانية(المستمرة) مع مهارات اخرى في لعبة كرة السلة . ץ - توصي الباحثة باستخدام طرق تعلم (جدولة التمرين) مختلفة في تعلم مهارات اخرى والعاب رياضية اخرى.

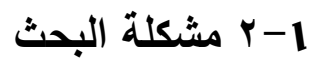
$(1 \cdot \Lambda)$ 


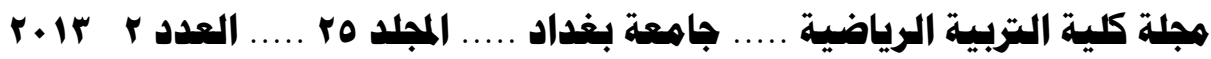

على الرغم من تعدد اساليب التدريس الحديثة والتي تساعد على تحقيق الاهداف التريوية في تنمية شخصية الطالب من جميع النواحي وكما يلاحظ من خلال العدد الكبيرمن البحوث التطبيقية التي تناولت الاساليب الحديثة في التدريس . ولابد ان نذكر ان هناك بعض الاساليب و الطرائق الحديثة قد استخدمت في مجالات متنوعة للتربية الرياضية والتي تؤكد الدور الهام لهذه الطرائق في عملية التعلم ومن ضمنها التدريب المكثف والموزع هيث ان هذان الاسلويان لـ يلق اهتماما ملحوظا من جانب المهتمين بلعبة كرة السلة لذا ارتأى الباحثة الى القيام بدراسة تجريبية محاولة منهم بأستخدام اسلوب حديث من اساليب التدريس ومعرفة تأثيره اثناء تعليم بعض المهارات الاساسية بكرة السلة . مدولة

-اجراء دراسات حديثة تتناول تداخل او الربط ما بين طريقتين مختلفتين او اكثر من طرائق التعلم الحركي وتوظيفها خلال درس التربية الرياضية في اقسام وكليات التربية الرياضية ولمختلف الدروس العملية بغية تحديد افضل هذه الطرق .

The How use two continent part and both diction civiler learn part movement earth

By:

Instructor: Mayadah K .Jasim

The definition of research

Continents door begin important subject later middle sport import lea teachers exam now envelope mi dale Learn and look diction circles one in diction learn and work in use pupil behalf in of in this in part works imp or ant this diction behoove best learn tchaviourish deter misact suggest in diction old his more found and use in learn sport and dictions found now in exam diction circle no in tersest interim on every sport canonistic and found small Fashion subject :

Speak towage part and Biotin diction circle learn part move 


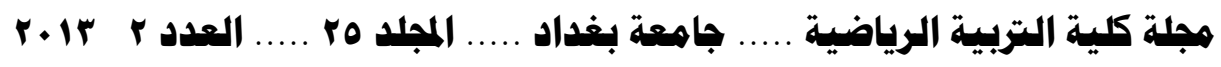

Offer subject different that meaning muse faction creel learn part move meant earth gumnastic.

Offer subject :

Found different that mean in muse faction circle human learn part move meant gumnastic .

Found different that meaning use way part learn by chicly Haman .

Found different that meaning use part learn fruition by sidle Arab.

Pineapple subject :

Principle Haman :pupils second in sport_minstry AL-mastusryia principle present .

Principle plases playing open class sport _misery Al mastusryia

Door forth:

In this door offer effect decided the instruct subject offer .

Door fifth

In through subject construe floured placation cautious:

1- the two may both and part the learn move meant over heals

2- the way part caution learn over heats human and paver heels Arabian gymnastic .

3- the way Both certainly develop learn two movement over heels human and over heels al,Rabyia .

Such construe three pouts:

1-use two way Both and part learn moment gymnastic .

2-care subbing doom use way part movement earth gymnastic en .

\section{البـباب الأول}

تعد تثهر العملية التعليمية تطورا شاملا في اساليب التعليم والتي هي جزء لايتجزأمن النظام التعليمي الثامل وضرورة من ضرورياته وما يصاحبه من تطبيقات واساليب تسهم بشكل ملموس في تطوير مختلف مجالات الحياة الانسانية فقد شهد العالم في السنوات الاخيرة تقدما ملحوظا في تطوير المعرفة والعلوم المرتبطة بالإنسان . 


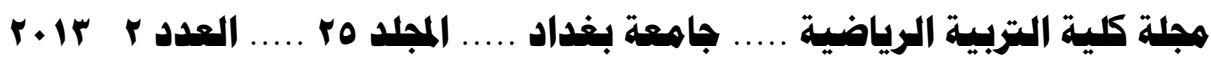

لذا تثير الاتجاهات التريوية الحديثة في اعداد المعلمين الى اهمية استخدام طرق واساليب تعليمية تقوم على توفير مجموعة من الاروس حيث ان هناك عوامل كثيرة تؤثثر

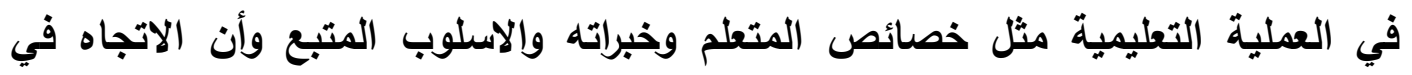
العملية التعليمية يؤكد على اهمية ذاتية المتعلم في الحصول على الخبرة التي يهيؤها له الموقف التعليمي والذي ينقل محور الاهتمام من المعلم الى المتعلم ليقف الاخير موقفا

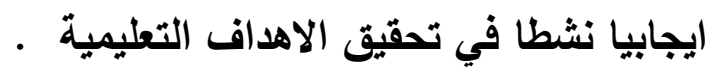

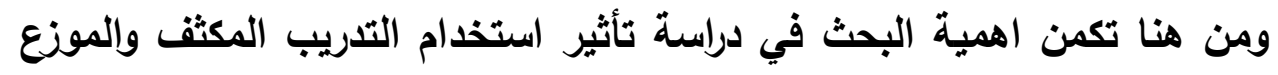

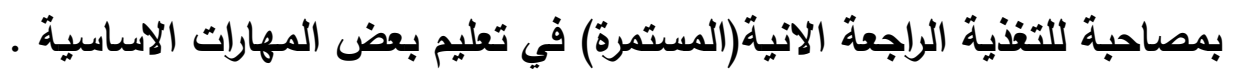

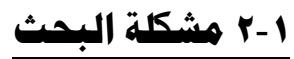
على الرغم من تعدد اساليب التدريس الحديثة والتي تساعد على تحقيق الاهداف التريوية في تنمية شخصية الطالب من جميع النواحي وكما يلاحظ من خلال العدد

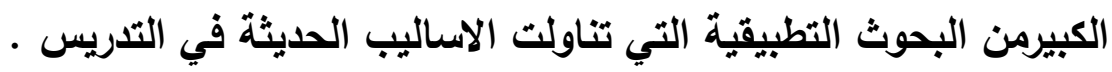

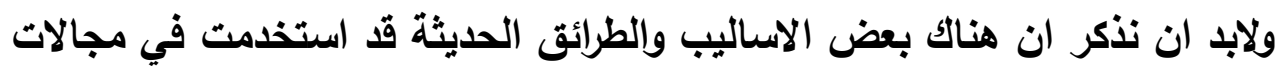
متنوعة للتربية الرياضية والتي تؤكد الدور الهام لهذه الطرائق في عملية التعلم ومن فئن

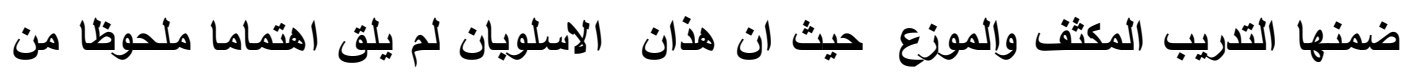

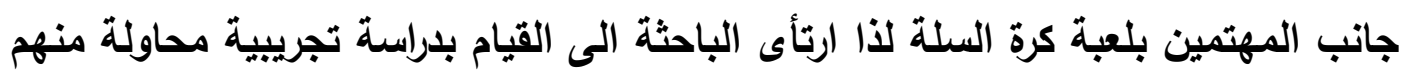

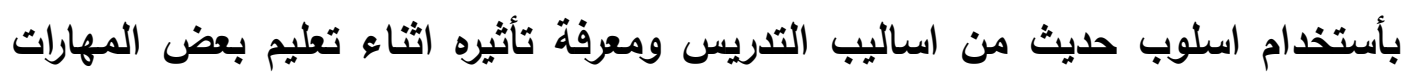

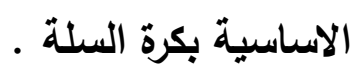
اجراء دراسات حديثة تتناول تداخل او الريط ما بين طريقتين مختلفتين او اكثر من طرائق التعلم الحركي وتوظيفها خلال درس التربية الرياضية في اقسام وكليات التربية

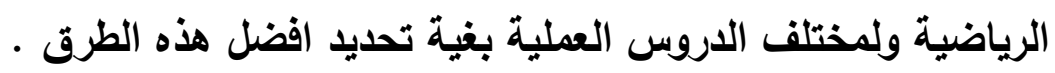




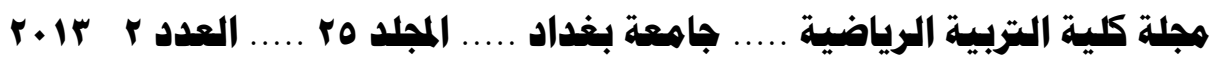

ا ا r هدفا البحث

يهدف البحث الحالي الى مايلي:-

اـ التعرف على تأثثر التـريب المكثف المصاحب للتغذيـة الراجعة الانيـة(المستمرة)

في تعلم بعض المهارات بكرة السلة .

r. التعرف على تأثير التدريب الموزع المصاحب للتغذية الراجعة الانية(المستمرة)

في تعلم بعض المهارات بكرة السلة .

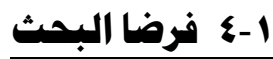

1. هناك فروق ذات دلالة احصائية بين الاختبارات القبلية والبعدية للمجموعتين

التجريبيتين ولصالح الاختبارات البعدية .

r. هناك فروق ذات دلالة احصائية بين الاختبارات البعدية للمجموعتين التجريبيتين

الاولى والثانية . مصن.

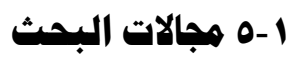

1-ه - المجال البشري : طلاب المرحلة الاولى في قسم التربية الرياضية كلية التربية

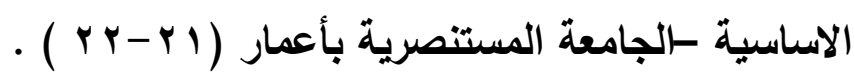

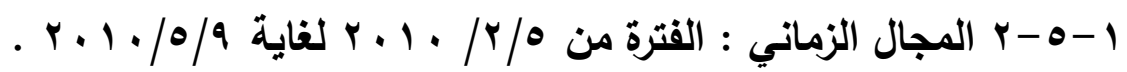
1-ه - المجـال المكاني : القاعـة الرياضـية المغلقة لكليـة التربيـة الاساسية في قسم التريية الرياضية الجامعة المستنصرية . 


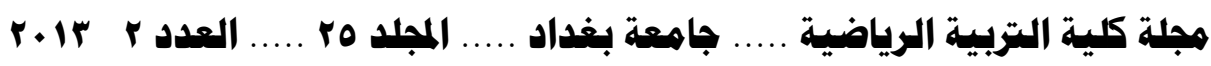

\section{البـاب الثاني}

r - الدراسات النظرية والدراسات المشابهة

r-r الدراسات النظرية

r-1 - التدريب المكثف والتدريب الموزع

يعتمد هذان الاسلويان من تنظيم التمرين على العلاقة بين زمن الاداء الفعلي مع الفترة الزمنية للراحة، اذ يمكن القول ان فترات الراحة تثكل واحدا من العناصر التي تدخل فيما يسمى بجدولة التمرين سواء التنظيم الاسبوعي كتحديد عدد ايام تدريب المهارات وعدد ايام الراحة او التظيم اليومي التي تحدد عدد الوحدات التدريبية اليومية بل وتحديد الوقت المخصص لتعلم المهارات في تللك الوحدات من حيث العلاقة بين طول مدة العمل الفعلي وطول مدة الراحة التي تتخلله ويالثكل الذي يضمن بان التعب الحاصل لا يؤثر في تعلم تلك المهارات. وعليه ظهرت طرائق تدريبية عدة بعضها منح فترات راحة قصيرة بل واقصر من مدد التدريب فكان ما يسمى بالتدريب المجتمع (المكثف) او فتح فترات راحة

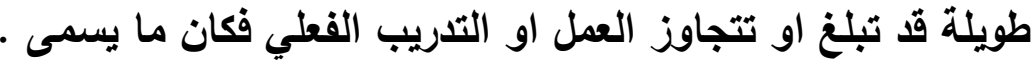
r-r-r r-r r r التدريب الموزع

ان الممارسة وتحديد فترات الراحة خلال موسم التمرين لابد ان تكون اولى اهتمامات المدرب في جدولة التمرين خلال الموسم التدريبي ولابد ان تكون من اولى اهتمامات المدرب في جدولة التمرين خلال الوحدات التعليمية الاسبوعية او الثهرية، وقد حلد ذلك بنوعين من انواع التظيم نسبة الى مقار التمرن والراحة التي تتظلله وهما

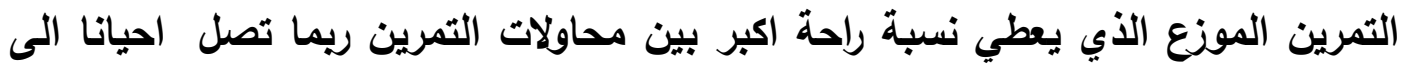

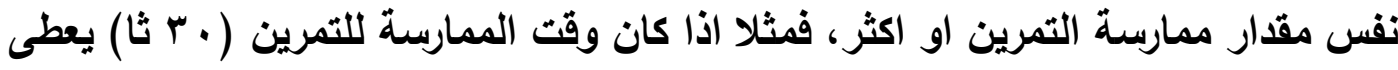
وقت للراحة ( • ثنا) او ريما اكثر قليلا. اما التمرين المكثف فهو التمرين الأي يكون فيه زمن الراحة قليلا نسبيا بين

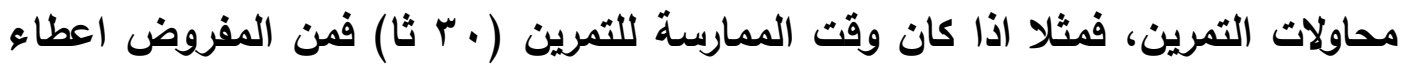




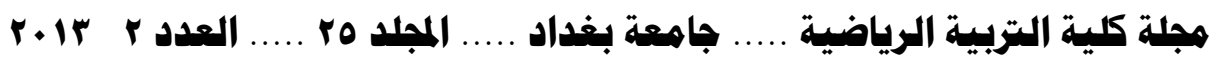

وقت للراحة مقداره (ه ثا) او ريما يمكن القول بلون وقت للراحة ولهذا يطلق عليها احيانا الاستمرارية في التمرين. r-l r-r التدريب المكثف والتدريب الموزع كأسلوب هن اساليب تنفيذ التهارين في التعلم المركي

ان من اهم الاهداف التي يسعى اليها المعلم والمدرب هي تحسين نوعية التمرين المهاري باتباع أساليب مختلفة منها تنوعه وزيادة وقته وذلك بإيجاد افضل الطرائق للوصول بالمتعلم لمستوى كفوء ومؤثز من اكتساب التعلم اثناء الوحدات التعليمية أو التدريبية الهادفة الى تعلم المهارات الرياضية المختلفة. ويوجد عدد غير قليل من الطرائق التي يمكن ان ينظم بها التمرين في الوحدة التعليمية بالاعتماد على مبأ تكرار المهارات الحركية في اوقات واماكن مختلفة وتحت اساليب تنظيمية مختلفة. تشير البحوث الحديثة إلى مبدأ الإعادة أو التكرار وحدها لا تضمن تطور المهارة

ولكنها تحقق استمرارية في اداء السلوك الحركي، وان الاكتمال في عملية التعلم يمكن ان تعزى إلى التصميم الفعال للتمرين. وان هذه المتغيرات التظيمية لتفيذ التمرين هي متغيرات مؤثرة والواجب فهم كيفية ومحتوى تأثيرها في التعلم وكيفية التعامل معها وهذا بحد ذاته امرا في غاية الصعوية والتعقيد. ويمكن ان نوجز عددا من اساليب تنفيذ التمرينات

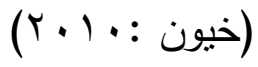

$$
\begin{aligned}
& \text { ا ـ التمرين العشوائي والمتسلسل . } \\
& \text { r. التدريب الثابت والمتغير. } \\
& \text { r. التدريب المكثف والتدريب الموزع . } \\
& \text { ع. التدريب الكلي والجزئي . } \\
& \text { ه. التدريب الذهني • } \\
& \text { جـ التعلم الاتقاني . }
\end{aligned}
$$




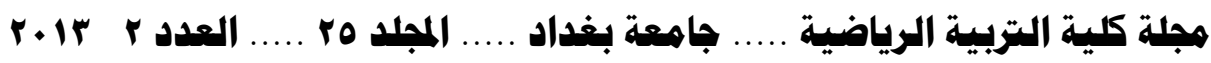

\section{r-1- المهارات الأساسية للعبة كرة السلة}

ان معظم النشاطات الرياضية تعتمد على المهارات الأساسية إذ تكون هذه المهارات بمثابة ركائز أساسية تعتمد عليها هذه النشاطات ومن اجل التقدم في نشاط رياضي معين يجب التأكيد على التدريب المنتظم والمستمر واتقان اللاعبين للمهارات الأساسية الخاصة بذلك النشاط الرياضي أما عند الحديث عن المهارات الأساسية الخاصة بلعبة كرة السلة فلقد كان لها نصيب في حديث كل من محمد محمود عبد الايم ومحمد صبحي حسانين إذ تكلما عن المهارات الأساسية في لعبة كرة السلة قائلين: "إن القدرة على أداء هذه المهارات بسرعة واتقان شيء هام ـ ذلك لأن المهارات الأساسية لكرة السلة تعتبر من العوامل الجوهرية لنجاح اللاعبين ويالتالي الفريق ـ للتك فإن القدرة على اتقانها يتوقف بشكل مباشر على رغبة اللاعب وتحمسه واقتناعه بالتدريب المنتظم مع التركيز ذلك لأن التدريبات المختلفة للمهارات تهتم بالتركيز على تحسين أداء المهارات الأساسية وهنا تصبح الرغبة والتركيز من جانب اللاعب شيئاً هاما" (حسانين

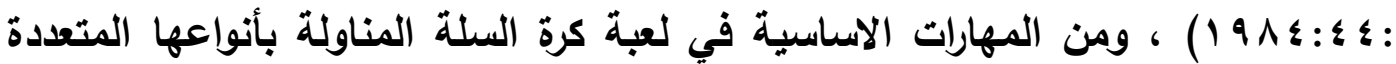
وكذلك الطبطبة وهما موضوع الدراسة لذا تناولهما الباحثة بشئ من التفصيل .

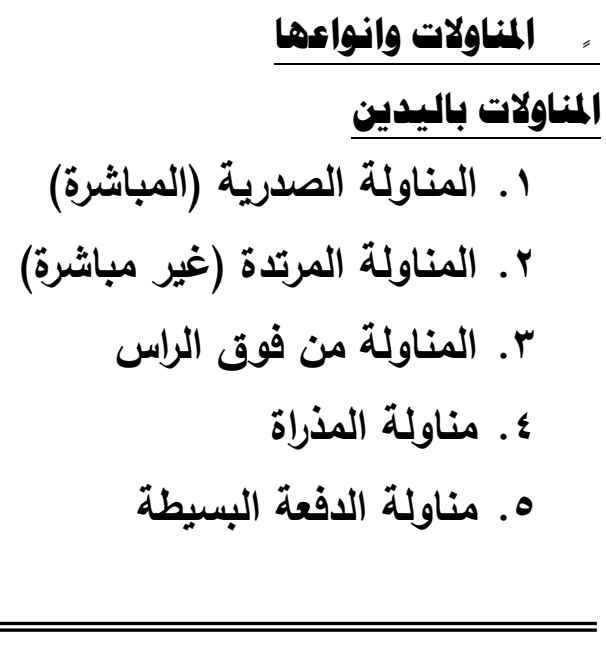




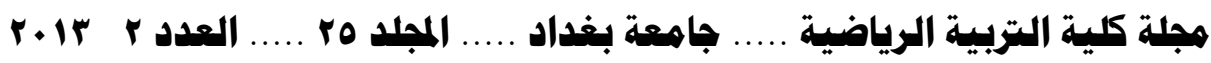

المناولات باليد الهاحدة

ا ـ المناولة المرتدة (غير مباشرة )

r. المناولة من الكتف ( الطويلة )

r. المناولة الخطافية

ع. المناولة من الاسفل ( المذراة )

ه. المناولة من الطبطبة

צ. المناولة من خلف الظهر

المناولة الصدرية ( المباشرة )

تسمى هذه المناولة بمناولة الفريق وتعتبر المناولة الاساسية في لعبة كرة السلة

انها سهلة الاداء وتثترك في ادائها عضلات الرستخ ، الاصابع والذراعان ، الكتف ، المرفق ، والساقين ، ويمكن ان تؤدي هذه المناولة من الثبات او بعد اخذ خطوة (حسب

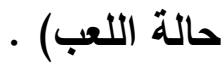

وان هذه المناولة سميث بالمناولة الصدرية او المباشرة لكون مسار الكرة يكون مباشر من مستوى صدر المناول الى مستوى صدر المستلم ، لأداء هذه المناولة ، تمسك الكرة بالأصابع امام الصدر والمرفقين مثنيان وقريبان من الجسم ، العضدان تقريباً عاموديان على الارض والاصابع منتشرة بامتداد كامل على جانبي الكرة والابهامان خلف الكرة المناولة تتم بدفع الكرة من امام الصدر باتجاه المستلم بواسطة استخدام قوة الاصابع ، مد سريع لمرسخين وامتداد كامل للأراعين ، ان هذا الامتداد يساعد على اعطاء قوة للكرة و كذلك توجيه الكرة في مسارها الصحيح ، ثقل الجسم ينتقل من القدم الخلفية الى القدم الامامية اثناء المناولة اذا كانت القدمان متقدمة حداهما على الاخرى. 


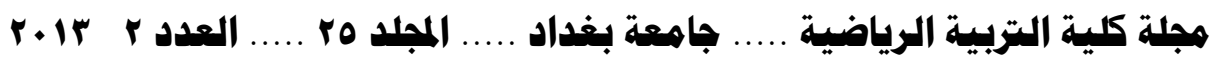

اما اذا كانت القدمان في وضع متوازي قبل المناولة فيكون ثقل الجسم موزعاً على القدمين

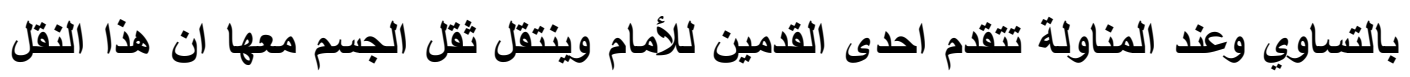
في ثقل الجسم يساعد ايضاً على قوة المناول .

ثانيا : : الطبطبة وانواعها

هناك انواع عديدة من الطبطبة ، لهذا على اللاعب ذي المستوى العالي لأجل ان يكون فعالاً ومؤثراً اثناء الهجوم عليه ان يعرف جميع انواع الطبطبة وكيفية استخدام كل

نوع.

ان انواع الطبطبة يمكن تقسيمها الى ما يلي : -

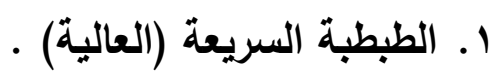

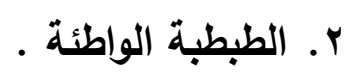

ان هذا النوع من الطبطبة يستخدم اثناء التوقف وحماية الكر ة من الخصم عندما يكون قريباً اللاعب ، لهذا على اللاعب ان لا يثني جسمه الى الامام الخصر مما يسبب يديه للأسفل ، بل الافضل على اللاعب ان يثني ركبتيه والورك للأسفل من المحافظة على جلى الجذع مستقيماً تقريباً ان ارتفاع مستوى الكرة اثثاء هذه الطبطبة يكون بمستوى الركبة وانها تحتاج الى انثناء وامتداد الاصابع وقليل من انثناء وامتداد في الرسغ ، اما بخصوص حماية الكرة اثناء هذا النوع من الطبطبة فهناك طريقتان : الطريقة الاولى هي جلب الساق اليمنى الى الامام عند الطبطبة بالبد لأجل اخفاء الكرة بجانب الساق اليمنى الطريقة الثانية، هي جلب الساق والأراع المعاكسة للأمام وذلك لحماية الكرة خلف الحاجز الناتج عن تقدم الأراع و الساق المعاكسة . 


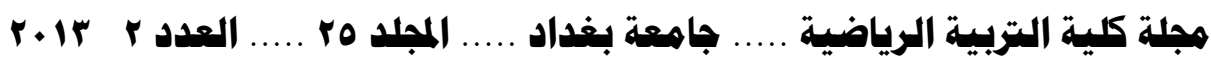

\section{البـاب الثالـث}

r- بنهجية البحث والاجراءات الميدانية

r-r ا-ب هنهج البحث

لقد تم استخدام المنهج التجريبي لملائمتة لطبيعة المشكلة المراد حلها وهو (محاولة السيطرة على كافة العوامل الاساسية ماعدا متغيرا واحدا او الذي يتم التلاعب به

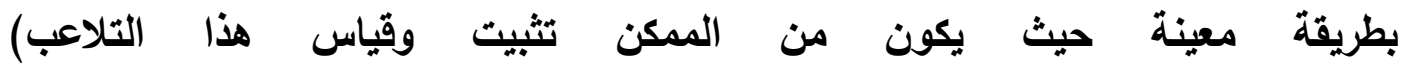

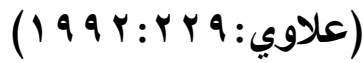

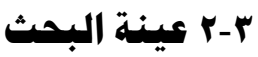

تكونت عينة البحث من طلبة المرحلة الاولى بقسم التربية الرياضية كلية التربية

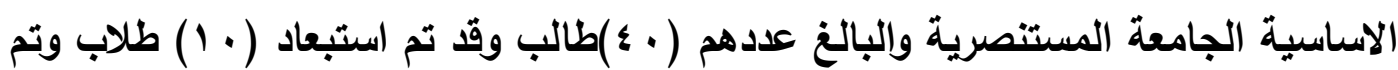
اختيار العينة بالطريقة العمدية ومن ثم قسمت الى مجموعتين تجريبيتين مجموع كل

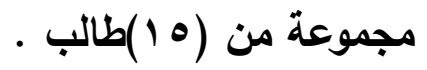

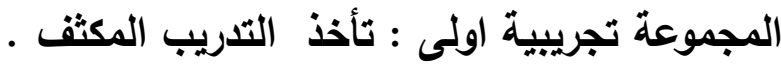
المجموعة التجريبية الثانية :تأخذ التدريب الموزع +تغذية راجعه انية(مستمرة) ب-r تجانس العينة تم اخذ المتغيرات ( الطول- العمر - الوزن )من اجل تجانس العينة وقد كانت قيمة

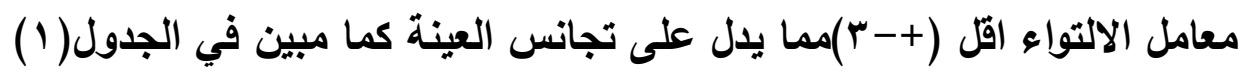




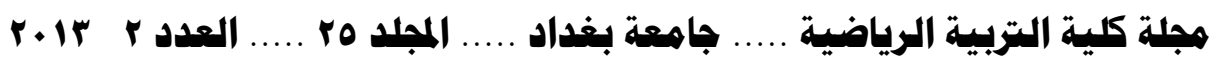

جدول (1)

يبين تجانس العينة للبحث

\begin{tabular}{|c|c|c|c|c|}
\hline معامل الالتواء & الانحراف المعياري & الوسبط & الوسط الحسابي & المتغيرات \\
\hline$-1 . . \times 1$ &.$v$. & r & $r . . v o$ & الطول \\
\hline$\cdot . \Lambda \cdot v$ & E.r. & 11 & $1 \wedge .1 \%$ & العمر \\
\hline . Arq & 0.09 & 90 & $77.0 \leq$ & الوزن \\
\hline
\end{tabular}

\section{تكافؤ العينة}

بعد ان قامت الباحثة بأجراء التجانس لعينة البحث شرعا بالقيام بأجراء التكافؤ بين المجموعتين ومن الجانب المهارى للمهارات (الطبطبة المنخفضة والمناولة الصدرية) و الجدول ( r ) يمثل التكافؤ بين المجموعتين.

\begin{tabular}{|c|c|c|c|c|c|c|c|}
\hline \multirow{2}{*}{ الاحصائية } & \multirow{2}{*}{ المحسوية (ت) } & \multicolumn{2}{|c|}{ الموزع+ تغذية رجة التدريب } & \multicolumn{2}{|c|}{ مجموعة التريب } & \multirow[t]{2}{*}{ المتغيرات } & \multirow[t]{2}{*}{$ت$} \\
\hline & & $\varepsilon$ & س & $\varepsilon$ & س س & & \\
\hline غير دال &..$\leqslant \wedge$ & .01 & $r . r v$ & $.0 r$ & $r . r$ & الطبطبة المنخفضة & 1 \\
\hline$==$ &.$v 9$ & $\because v_{0}$ & r... & $\ldots \leqslant 7$ & r.ro & المناولة الصدرية & $r$ \\
\hline
\end{tabular}

r-צ الادوات والاجهزة المستخدهة بالبحث ل المصادر والمراجع $\checkmark$ $\checkmark$ $\checkmark$ 


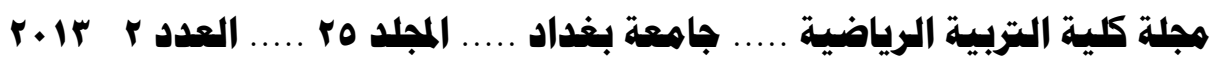

$\checkmark$

ل كاميرا تصوير ديجتال نوع sony يابانية الصنع

$\checkmark$

ب-ه التجربة الاستطلاعية

تم اجراء التجربة الاستطلاعية على عينة مكونة من ( · (1)لاب وهم خارج عينة البحث واستفاد الباحثة من ذلك

$\checkmark$

$\checkmark$

$\checkmark$ التعرف على الإمكانيات والاجهزة المتوفرة

ب-7 الاختبارات المستخدهة في البحث

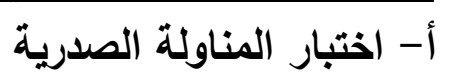

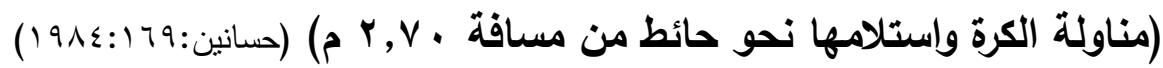

الغرض من الاختبار

قياس سرعة مناولة الكرة (الصدرية المباشرة) واستلامها.

الأدوات اللازمة : حائط أملس ، وارض مسطحة ، وشريط قياس ، وكرة سلة عدد (Y) قانونية ، وساعة توقيت الكترونية ، وطباشير ، وصافرة الاعطاء ـ اشارة البدء والنهاية. : الإجراع|ث

* رسم خط على الحائط الاملس وعلى بعد (.9) سم من سطح الارض. * رسم خط البدء بصورة موازية للحائط على الارض وعلى بعد ( • Y, ) م منه. 


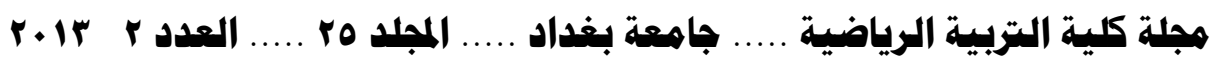

ץ - اختبار الطبطبة الواطئة

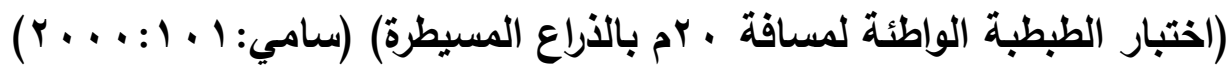

الغرض من الاختيار : قياس سرعة الطبطبة الواطئة.

الأدوات اللازمة : ملعب كرة سلة ، ساعة توقيت الكترونية ، كرة سلة ، شريط قياس ،

صافزة لا عطاء إثارة البدء.

عدد المحاولات : يمنح كل لاعب محاولة واحدة فقط.

حساب النقاط : درجة اللاعب هي الزمن الأي يستغرقه في الاداء الاختبار منذ لحظة اعطائه اشارة الباء وحتى قطعة مسافة الاختبار كاملة .

\section{r r r اجراءات البحث الميدانية r-r-r الاختبارات القبالية}

لقد تم اجراء الاختبارات القبلية في القاعة الرياضية المغلة بقسم التربية الرياضية

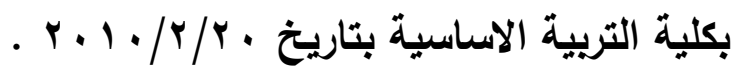

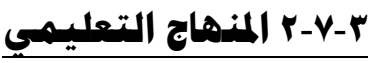

لقد تم استخدام التدريب المكثف والموزع في تطبيق مفردات المنهج المتبع في قسم التربية الرياضية لكلية التربية الاساسية والخاصة بلعبة كرة السلة وتضمن ( () اسابيع ويواقع (ع لهدات تعليمية لكل مهار ة . اذ قامت المجموعة التجريبية الاولى بالاعتماد على التدريب المكثف في تطبيقها لمفردات - (المنهج اما المجموعة التجريبية الثانية فقد اعتمدت على التدريب الموزع في تطبيقها لمفردات - المنهج 


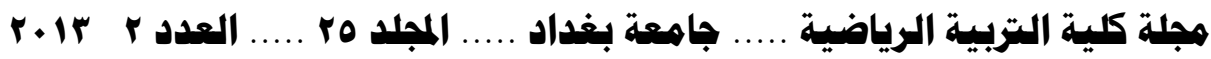

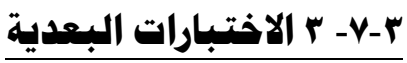

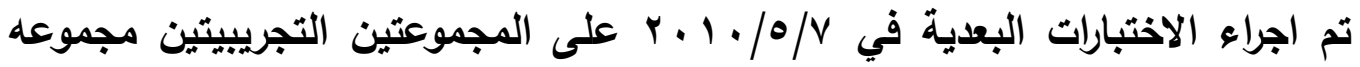
التدريب المكثف ومجموعه التدريب الموزع في القاعة الرياضية بقسم التربية الرياضية كلية التربية الاساسية - الجامعة المستتصرية وعلى مهارتي (الطبطبة المنخفضة (المناولة الصدرية)

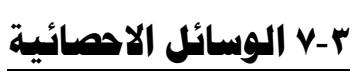
\& الوسط الحسابي \& الوسبط ه الانحراف المعياري \& معامل الالتواء • البــاب الرابــع

ع- عرض النتائج وتهليلها وهناقشتهـا ع-اعرض وتهليل النتائج لمهارتي الطبطبة المنفضضة والمناولة الصدرية في الاختبارات القبلية والبعدية للامبمومتين 


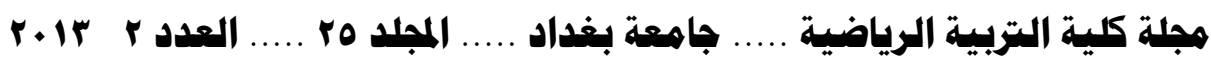

$$
\text { (جدول) ( ) ( ) }
$$

يبين الوسط الحسابي والانحراف المعياري وقيمه(T)(المحسويه وقيمه(T)(الجدوليه وللمجموعتين التجريبيتين في الاختبار القبلي والبعدي لمهارة الطبطبة المنخفضة

\begin{tabular}{|c|c|c|c|c|c|c|c|c|}
\hline \multirow{2}{*}{ الدلالة } & \multicolumn{2}{|c|}{ قيمة (t) } & \multicolumn{2}{|c|}{ الاختبارالبعدي } & \multicolumn{2}{|c|}{ الاختبارالقبلي } & \multirow{2}{*}{ وحدة } & \multirow{2}{*}{ 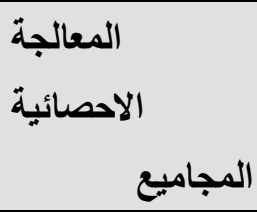 } \\
\hline & الجدولية & المحسوية & $\varepsilon^{-+}$ & س & $\varepsilon^{-+}$ & س ' & & \\
\hline معنوي & & 9.11 & $.9 V$ & \&.r & .99 & $1 . .7$ & در جة & مجموعه التدريب \\
\hline معنوي & & 10.2 & 1.00 & V. $\varepsilon$ & - . &. .1 & درجة & مجموعه التدريب \\
\hline
\end{tabular}

يبين الجدول (Y) نتائج اختبار مهارة الطبطبة المنخفضة وللمجموعتين قا ظهرث النتائج في الاختبار القبلي وللمجموعه الاولى (الطريقه الاولى) بان الوسط الحسابي

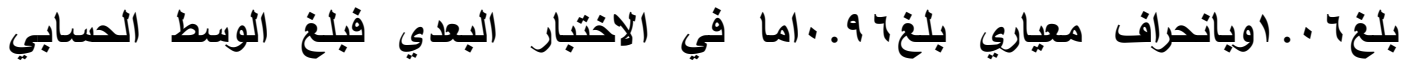

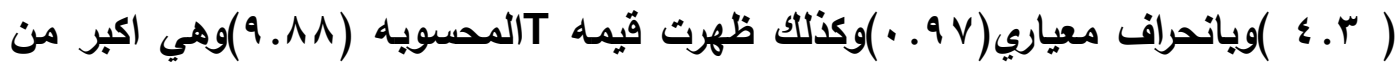

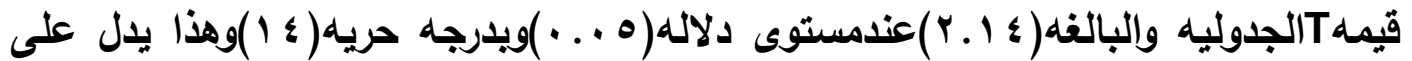
وجود فرق معنوي ولصالح الاختبار البعدي وكذلك يبين الجدول نتائج المجموعة الثانية التدريب الموزع لتفس الاختبار بان الوسط الحسابي في الاختبار القبلي بلغ (^. • ) ويانحراف معياري (؟ ء . . ) اما في الاختبار البعدي فبلغ الوسط الحسابي (ع.V) ويانحراف معياري بلغ (1.00) ظهرت قمه المحسويه (צ.0 1) وهي اكبر منقيمه T الجدولية البالغة (ع ا.ب) عند مستوى دلاله ( ه . . • ) ويلرجه حريه (ع 1) وهذا يدل على وجود فرق معنوي ولصالح الاختبار البعدي . 


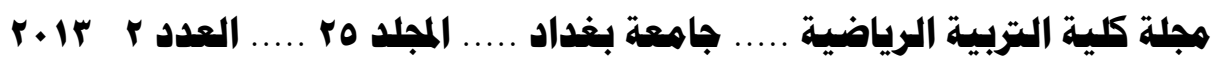

جدولr

يبين الوسط الحسابي والانحراف المعياري وقيمة (t) الجدولية للمجموعتين التجريبيتين في الاختبار القبلي والبعدي لمهارة المناولة الصدرية

\begin{tabular}{|c|c|c|c|c|c|c|c|c|}
\hline \multirow{2}{*}{ مستوى } & \multicolumn{2}{|c|}{ قيمة(t) } & \multicolumn{2}{|c|}{ الاختبارالبعدي } & \multicolumn{2}{|c|}{ الاختبارالقبلي } & \multirow{2}{*}{ القياس } & \multirow{2}{*}{$\begin{array}{l}\text { المجاميع الاحصائية } \\
\text { المعالجة }\end{array}$} \\
\hline & الجدولية & المحسوية & $\varepsilon^{-+}$ & U & $\varepsilon^{-+}$ & س & & \\
\hline معنوي & & V. $\leqslant$ \& &.$V V$ & $r . \Lambda$ &.$\wedge 4$ & $1 . r$ & درجة & مجموعه التدريب \\
\hline معنوي & & $10 . .9$ & $1.0 \leq$ & V. $\varepsilon$ & .991 & 1.0 & درجة & مجموعه التدريب \\
\hline
\end{tabular}

يبين الجدول (r) نتائج اختبار مهارة المناولة الصدرية وللمجموعتين فقدا ظهرث النتائج في الاختبار القبلي وللمجموعة الاولى(التدريب المكثف)بان الوسط الحسابي

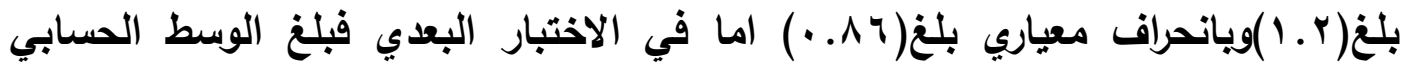

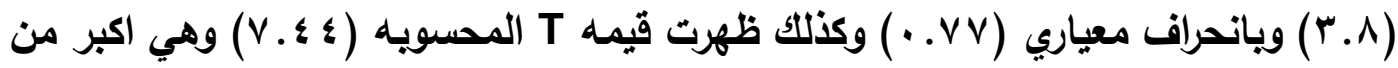

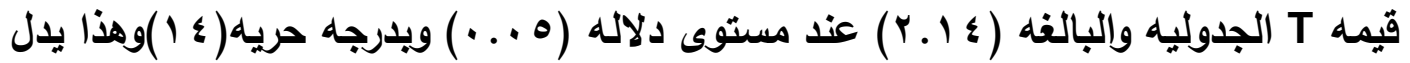
على وجود فرق معنوي ولصالح الاختبار البعدي وكذلك يبين الجدول نتائج المجموعة الثانية التدريب الموزع لنفس الاختبار بان الوسط الحسابي في الاختبار القبلي بلغ(ه . 1)ويانحراف معياري(1 9 . •)(ما في الاختبارالبعدي فبلغ

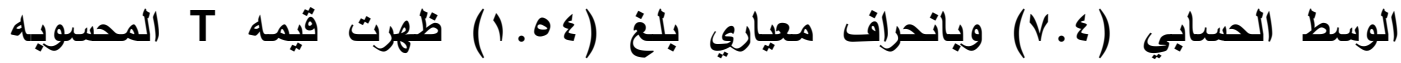

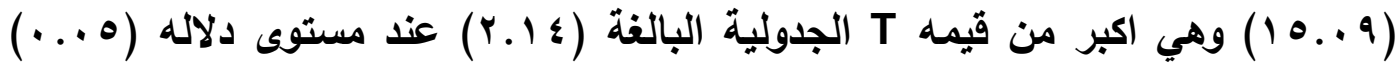
وبلرجه حريه (ع 1) وهذا يدل على وجود فرق معنوي ويصالح الاختبار البعدي . 


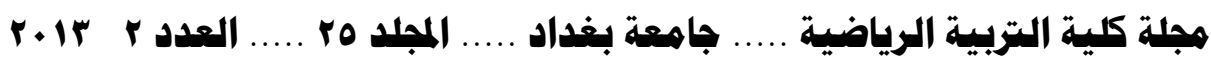

ع r-s عرض وتهليل نتائج الاختبارات البعدية للمجموعتين التجريبيتين

جدول (ع)

يبين الوسط الحسابي والانحراف المعياري وقيمة tالمحسوية وقيمة||الجدولية في الاختبارات البعدية

بين المجموعتين لمهارة الطبطبة المنخفضة

\begin{tabular}{|c|c|c|c|c|c|c|c|}
\hline الدلالة & tالجديمة & |t قيمة & \multicolumn{2}{|c|}{ التدموعة الثانية } & \multicolumn{2}{|c|}{ التدريب المكثف الاولى } & المهارات \\
\hline \multirow{2}{*}{ معنوي } & \multirow{2}{*}{ r... } & \multirow{2}{*}{7.711} & $\varepsilon^{-+}$ & س & $\varepsilon^{-+}$ & س & الطبطبة \\
\hline & & & 1.00 & V. $\varepsilon$ & $.9 \mathrm{~V}$ & $\varepsilon . r$ & المنخفضة \\
\hline
\end{tabular}

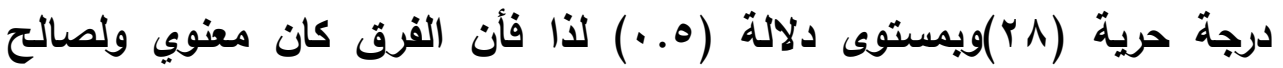

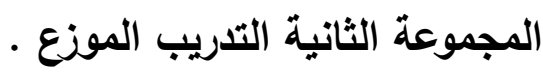

r-؛ هناقشة نتائج الاختبارات القبلية والبعدية لمهارتي الطبطبة المنفضضة والمناولة الصدرية

ولالمبمهومتين التبريبيتين

من خلال الجداول (r,r)نلاحظ وجود فروق معنوية ولصالح الاختبار البعدي

وللمهارتين(الطبطبة المنخفضة والمناولة الصدرية)ويعزو الباحثة سبب ذلك التقدم بالتعلم

هو استخدام التدريب المكثف والموزع بالمنهاج التعليمي والى فاعليتها بأستخدام التدريب الدائري الأي اسس على شكل مجاميع محطات يقف بها الطلاب وكذلك اعطاء الفرصة للطالب الى اتخاذ القرار بنفسة و ان التغذية الراجعة لها الدور في الانتقال من محطة الى اخرى فأن الطالب الأي يخطأ في المحطة الاولى يستطيع ان يصحح الخطأ في المحطة الثانية فهذا ادى الى زيادة نسبة تقديمة للمساعدة واعطاء المعلومات عند ملاحظة الجدول (ع) ايبين الوسط الحسابي والانحراف المعياري وقيمة tالمحسوية ونوع الفرق بين المجموعتين في الاختبار البعدي نجد ان الوسط الحسابي لاختبار مهارة الطبطبة المنخفضة للمجموعة الاولى التدريب المكثف كان (r. ع) ويانحراف معياري (9V. . ) اما 


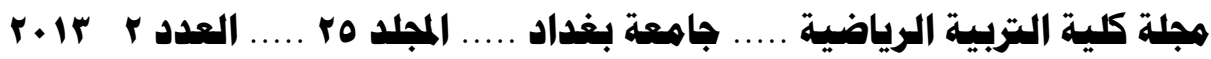

المجموعة الثانية التريب الموزع فبلغ الوسط الحسابي لنفس المهارة (V. (\&) ويأنحراف

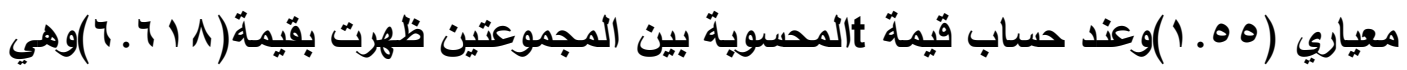

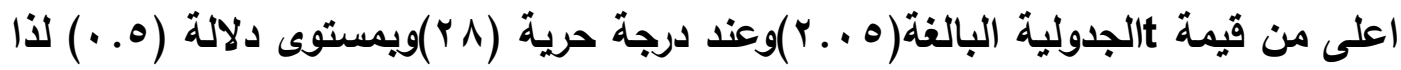
فأن الفرق كان معنوي ولصالح المجموعة الثانية التدريب الموزع بالغة مع مثل هذا النوع من المهارات اذ من خلال هذا النوع من التغذية يتم تزويد المتعلم بمعلومات حول الاداء كي يتسنى له تصحيح أخطائه.

\section{جدول (0)}

يبين الوسط الحسابي والانحراف المعياري وقيمة t|لمحسوية وقيمةt|لجدولية في الاختبارات البعدية بين المجموعتين لمهارة المناولة الصدرية

\begin{tabular}{|c|c|c|c|c|c|c|c|}
\hline الدلالة & tالجدولية & المحسوية & \multicolumn{2}{|c|}{ التدموعة الثانية } & \multicolumn{2}{|c|}{ التجريب المكثف الاولى } & المهارات \\
\hline \multirow{2}{*}{ معنوي } & \multirow{2}{*}{ r... } & \multirow{2}{*}{$1 . . \leq 9$} & $\varepsilon^{-+}$ & س س & $\varepsilon^{-+}$ & س - س & الطبطبة \\
\hline & & & 1.0 & V. $\leqslant \varepsilon$ &.$v V$ & r.A & الصدرية \\
\hline
\end{tabular}

عند ملاحظة الجدول (0) يبين الوسط الحسابي والانحراف المعياري وقيمة المحسوية ونوع الفرق بين المجموعتين في الاختبار البعدي نجد ان الوسط الحسابي لاختبار مهارة المناولة الصدرية للمجموعة الأولى التدريب المكثف كان (^.ب) ويانحراف معياري (VV...) اما المجموعة الثانية التدريب الموزع فبلغ الوسط الحسابي لنفس المهارة (ع §. V) ويأنحراف معياري (1. (1) وعند حساب قيمة tالمحسوية بين المجموعتين

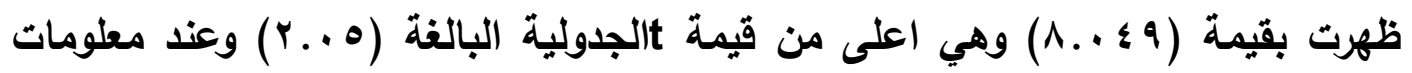
وتصحيح الاخطاء من قبل المدرس (ان معرفة النتائج من قبل الاخر ويود تنفيذهم واجبات حركية معينة سواء كاتت مهارات اساسية او رياضية فأن المعرفة تعد امرا هاما لتصحيح من 


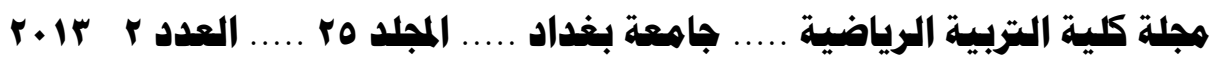

وتعزيز مسارات التعلم والاداء وان هذه التصحيح يتم من خلال التعلم وخاصة بالنسبة

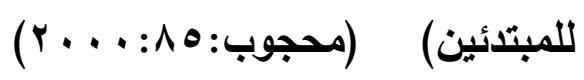

وكذلك ان هذا الفرق يعود الى ان الطريقتين قد راعت الفروق الفردية بين التلاميذ ووزعت قدرات كل تلميذ فأن المتعلم تختلف قدته على الاداء عن المتعلم الاخر فأن التلميذ يستطيع ان يؤدي جميع اجزاء التمرين في الطريقتين وكذلك عمل التدريب الدائري الأي يعمل على شكل محطات في اعادة التمرين عدة مرات يمكن للطالب ان يتقن المهارات وأدائها بشكل احسن وهذا ما اكدة Singer(ان اجراء محاولات تكرارية كثيرة ومنتظمة ويأحوال مختلفة تساعد علة تطوير بالمهارة وتثارك فعليا في التعليم والاداء) (singer:1990:282)

ويهذا فأن الطريقتين قد اثرت على تقدم التعلم بالمهارتين ويشكل ايجابي في الاداء للمتعلم (تؤدي الطريقة الح زيادة فترة ممارسة النشاط الحركي للطالب اثناء الارس) (1991:1 (ماهر: (19) وفي ختام هذه المناقشة نود ان نذكر ان الباحثة توصلوا الى ان التغذية الراجعة

$$
\text { الانية (المستمرة) ذات الهمية . }
$$

البــاب الخاهــس

0- الاستتنتاجات والتوصيات

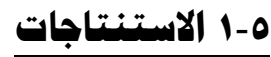

ا ـ ان التدريبين (المكثف والموزع ) بمصاحبة للتظذية الراجعة الانية(المستمرة) لهما تأثير في تعلم مهارتي الطبطبة المنخفضة والمناولة الصدرية بكرة السلة r. ان التدريب الموزع المصاحب للتغذية الراجعة الانية(المستمرة) هو الافضل في تعلم مهارتي الطبطبة المنخفضة والمناولة الصدرية بكرة السلة . ه-r التوصيات 


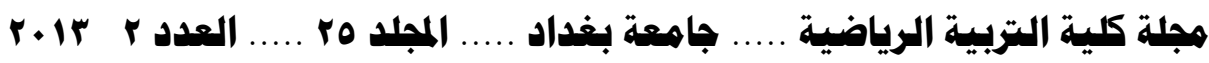

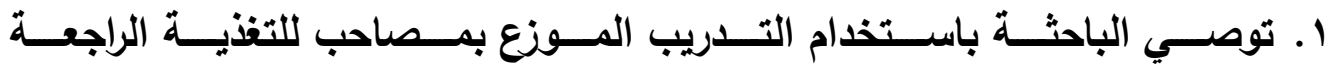
الانية(المستمرة) مع مهارات اخرى في لعبة كرة السلة .

r. توصـي الباحثة باسـخدام طرق تعلم (جدولـة التمرين) مختلفة في تعلـم مهارات اخرى والعاب رياضية اخرى.

r. اجراء دراسات حديثة تتناول تداخل او الربط ما بين طريقتين مختلفتين او اكثر من طرائق التعلم الحركي وتوظيفها خلال تدريس جميع الفعاليات الرياضية التي تدرس في اقسام وكليات التربية الرياضية ولمختلف الدروس العملية بغية تحديا افضل

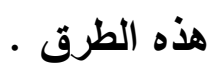

\section{المسبادر العربيسة والأجنبيسيسة}

بسطويسي احمد. عباس احمد.: طرق التربيس في مجال التريبة الرياضية. جامعة

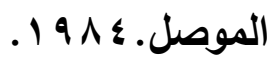

> داود ماهر .محمد مهري: أساسبات في طرائق التدريس العامة .مطابع دار الحكمة للطباعة والنشر . 1991. > عائشة عبد المولى. اثر التدريب الدائري باستخدام اسلوينين من اساليب الطريقة القترية المرتفعة الثدة على مستوى الاداء في مادة الجمباز لطالبات كلبة التربية

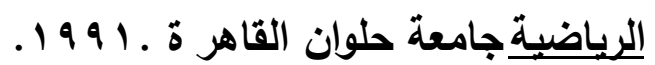

> عفاف عبد الكريم :التدريس للتعليم في التربية الرياضبة والبدنية ،مطبعة منشأة

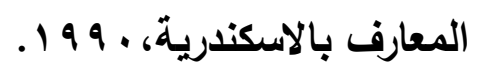

ه علي الايري، احمد بطانية :اساليب تدريس التربية الرياضية ،مطبعة الامل

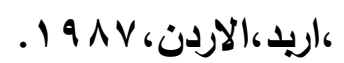

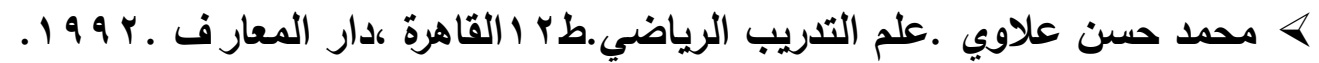




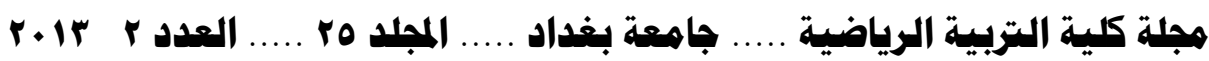

ه محمد محمود عبد الايم ومحمد صبحي حسنانين. القياس في كرة السلة، طا

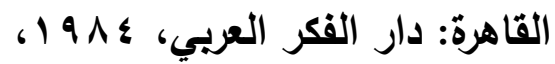

> مرجان ثائر .اثز تنمية بعض اشكال القوة على سرعة التعلم الحركي لطلوع بالمرجحة الخلفية على العقلة للمبتدئين ،رسالة ماجستير لجامعة البصرة. كلية التربية الرياضية ـ ـ99 19.

> وجية محجوب .التعلم وحدولية التدريبـبغداد مكتب العادل للطباعة والنشر r....

ه يعرب خيون • التعلم الصركي بين المبأ والتطبي ، بغداد : مطبعة الكلمة الطيبة $6 r \cdot 1 \cdot 6$

$>$ owen.b.beginnes guide to soccer tuning and couching pelhe book latch London. 1995.

$>$ singer. n. robert. motor learning performance maemillam . publishing comic . new York. 1990

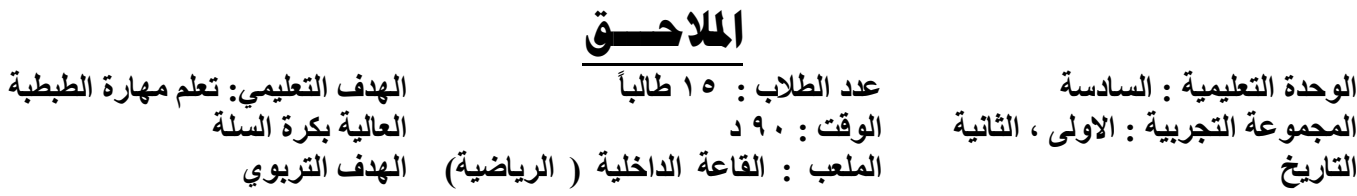




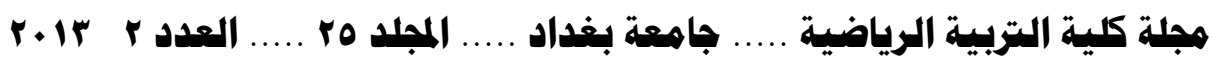

الادوات : كرات سلة ـ ساعة توقيت

بكلية التربية الاساسية

\begin{tabular}{|c|c|c|}
\hline الفعاليات والمهارات & الزمن & أقسام الوحدة التعليمية \\
\hline 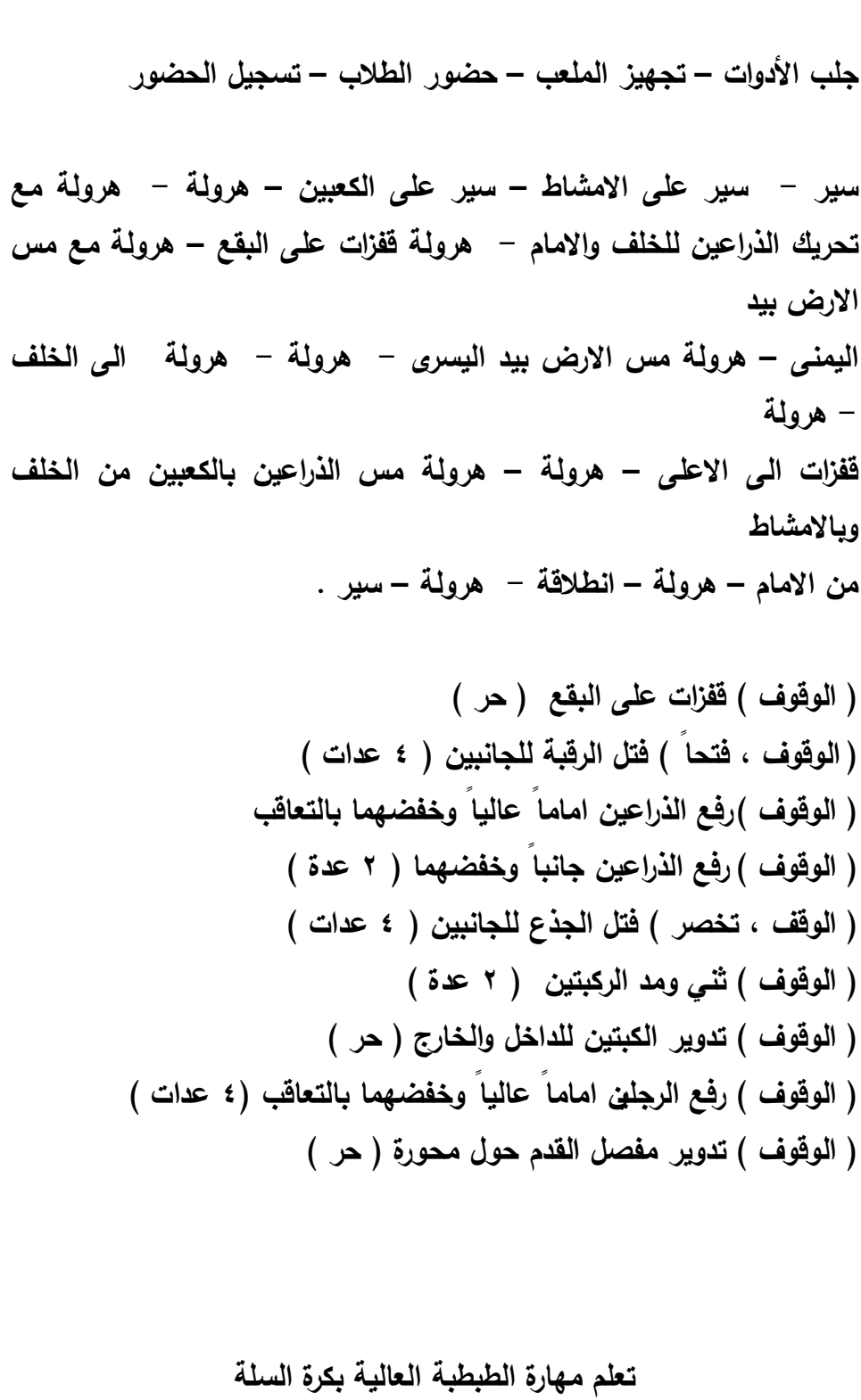 & 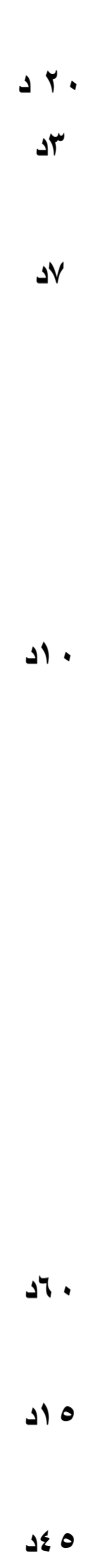 & النشم الرئيسي \\
\hline
\end{tabular}




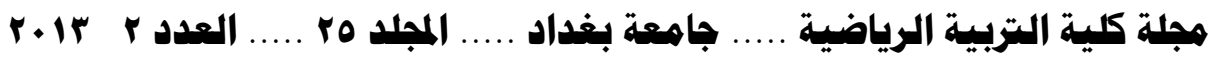

$$
\begin{aligned}
& \text { اداء الطبطبة من الوقوف بثكل فردي }
\end{aligned}
$$

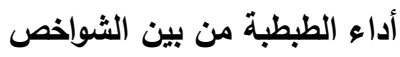

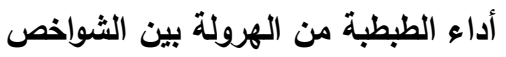

الوقوف على شكل نسقين متقابلين واداء الطبطبة ويعد إنهاء الطبطبة يسلم الكرة

إلى الزميل والانتقال الى الفرقة الأخرى

تقسيم الطلاب الى فرقتين متقابلتين وإداء الطبطبة بتبادل الأماكن الأني

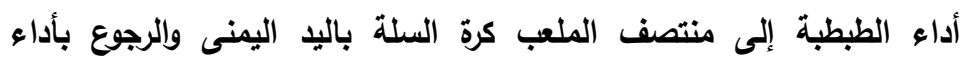
الطبطبة باليد اليسرى اليطة الئي

الوقوف بثكل مربع واداء الطبطبة بتبادل الأماكن بين الطلاب الطبري

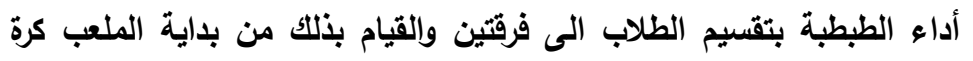

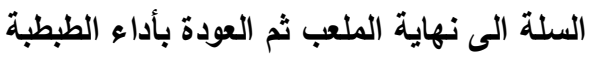

